\title{
CONHECIMENTOS LOCAL E CIENTÍFICO SOBRE SOLOS: O CASO DOS AGRICULTORES FAMILIARES DE ANTONINA E MORRETES - PR.
}

\author{
Andressa Kerecz Tavares ${ }^{1}$ \\ Marcelo Ricardo de Lima²
}

\begin{abstract}
RESUMO
O estudo tem por objetivo aproximar o conhecimento sobre solos de agricultores e cientistas através da correspondência de classes etnopedológicas e científicas. Foram entrevistadas vinte famílias de agricultores de Antonina e Morretes (PR) através da metodologia de diagnóstico participativo. As classes de solos identificadas foram ordenadas conforme as técnicas científicas formais. Foram abertos dois perfis complementares para cada classe etnopedológica para averiguar as correspondências entre as classes de terras nos municípios pesquisados. Para a classificação cientifica utilizou-se o Sistema Brasileiro de Classificação de Solos (SiBCS). Obteve-se como resultados a classe etnopedológica "Terra de Morro" que correspondeu às classes de solos CAMBISSOLO HÚMICO Distrófico típico e ARGISSOLO VERMELHO-AMARELO Distrófico típico, a terra "Sabão de Caboclo" correspondeu a GLEISSOLO HÁPLICO Tb Distrófico típico e GLEISSOLO HÁPLICO Ta Eutrófico típico, a "Terra Argilosa" correspondeu a CAMBISSOLO HÁPLICO Tb Distrófico típico e CAMBISSOLO HÁPLICO Ta Eutrófico típico, e a "Terra de Desmonte" correspondeu a CAMBISSOLO FLÚVICO Ta Distrófico típico e NEOSSOLO FLÚVICO Ta Eutrófico típico. Os sistemas de classificação de agricultores é voltando ás necessidades produtivas agrícolas, artesanais ou para construção de moradias, já o sistema de classificação de cientistas do solo o SiBCS aplicado tem objetivo geral e empregos em diversas áreas.
\end{abstract}

Palavras-chave: atributos diagnósticos, classificação de solos, etnopedologia, litoral do Paraná, percepção de agricultores.

\section{LOCAL AND SCIENTIFIC KNOWLEDGE OF SOIL: THE CASE OF FAMILY FARMERS OF ANTONINA AND MORRETES IN THE STATE OF PARANÁ.}

\footnotetext{
ABSTRACT

This study aims to verify the similarities and differences between the knowledge of farmers and scientists on soil through the correspondence of etnopedological and scientific classes. Also analyze comparatively the ways farmers and scientists analyze soils. For the ethnopedological research twenty farm families were

1 Graduada em Engenharia Agronômica (UFPR). Mestrado em Ciência do Solo (UFPR). Doutoranda em Ciência do Solo (UFPR). Professora da Universidade Federal do Paraná - Setor Litoral. E-mail: andressa.tavares@ufpr.br

2 Graduado em Engenharia Agronômica (UFPR). Mestrado em Ciência do Solo (UFRGS). Doutor em Produção Vegetal (UFPR). Professor da Universidade Federal do Paraná. Setor de Ciências Agrárias. Departamento de Solos e Engenharia Agrícola. E-mail: mrlima@ufpr.br
} 
interviewed. The classes of land identified by farmers were also classified according to the formal scientific techniques, has been open two additional profiles for ethnopedological class to verify whether there were differences between the lands. For the formal classification the Brazilian System of Soil Classification was used as reference. The result obtained was that the class ethnopedological "Terra de Morro" corresponded to CAMBISSOLO HÚMICO Distrófico típico and ARGISSOLO VERMELHO-AMARELO Distrófico típico, the "Sabão de Caboclo" corresponded to GLEISSOLO HÁPLICO Tb Distrófico típico and GLEISSOLO HÁPLICO Ta Eutrófico típico, the "Terra Argilosa" corresponded to CAMBISSOLO HÁPLICO Tb distrófico típico and CAMBISSOLO HÁPLICO Ta Eutrófico típico, and "Terra de Desmonte" corresponded to CAMBISSOLO FLÚVICO Ta Distrófico típico and NEOSSOLO FLÚVICO Ta Eutrófico típico. Farmer classification systems are returning to productive agricultural, artisanal or housing construction needs, whereas the SiBCS soil scientist classification system applied in this research has a general purpose that can be employed in various uses.

Key words: diagnostic attributes, ethnopedology, farmers perception, Paraná coastline Paraná coastline, soil classification.

\section{INTRODUÇÃO}

A ciência contemporânea passa por uma de mudança de paradigma, surge a necessidade de repensar os métodos científicos. As discussões atuais demonstram o empenho de vários especialistas na crítica da ciência convencional, na construção de alternativas e uma forma de orientar sua relação com a sociedade, tornando-a democrática e inclusiva (GOMES,1999; GOMES, 2011).

Dentro desta atmosfera emergem estudos que avançam as fronteiras dos métodos tradicionais de se produzir o conhecimento científico, segundo Alier (2014), existe a necessidade de se considerar simultaneamente diversas formas de conhecimento apropriadas para diferentes níveis de análise. Nas Ciências Agrárias, especificamente na área de Ciência do Solo verifica-se uma ascensão de pesquisas sobre os saberes locais sobre solos atualmente denominados de conhecimentos etnopedológicos.

A etnopedologia é uma disciplina que estuda a percepção camponesa das características e processos do solo, incluindo nomenclatura e taxonomia, a relação com fatores ecológicos, assim como manejo agrícola e sua utilização em outras atividades produtivas e também analisa as paridades entre o saber tradicional e os científicos (BARRERA-BASSOLS,1988).

Comumente estudos etnopedológicos são etapas iniciais e essenciais nas pesquisas sobre solos durante a fase de campo e frequentemente os pesquisadores consultam os habitantes locais (ALVES et al., 2006). Atualmente a etnopedologia se incorpora e avança nos programas de pesquisa e aponta a necessidade de se incluir novos métodos de observação (ARAÚJO et al., 2013).

Neste sentindo ressalta-se que os conhecimentos em etnopedologia apresentam similaridades ao cientifico principalmente aos atributos observados, classes de solos e métodos de análise a campo (ERICKSEN ; ARDÓN, 2003; ALVES et al., 2005; BENASSI et al., 2009; PALACIO; ARRIAGA, 2005; DAWOE et al., 2012; ALTIERI, 2012; CARVALHO, 2016; PORTELA et al., 2015; NETO, et al., 2019). Ainda para diversos autores a aproximação das interpretações, locais e cientificas, sobre o solo contribui para uma gestão sustentável das terras, pois tanto as análises locais como as científicas são incompletas e estas podem ser 
complementares (BRIGGS et al., 1998; TALAWAR; RHOADES, 1998; ERICKSEN; ARDÓN, 2003; ALIER, 2014; ALTIERI, 2012; STRACHULSKI; FLORIANI, 2014).

As similaridades e complementariedades, entre os conhecimentos locais e científicos, apontam para a possibilidade de construção de um conhecimento inclusivo e que atenda as necessidades humanas e ambientais. Nesse contexto, estudiosos apontam a necessidade de se construir um conhecimento inclusivo, para além de facilitar sua aplicabilidade em escalas singulares também ser ecologicamente ajustado às condições globais (ALTIERI, 2012; ALIER, 2014).

Ainda sobre a necessidade de mudança de paradigmas, estudos apontam que um dos maiores problemas da agricultura moderna é a desconsideração, desconexão das culturas locais especialmente em países tropicais e pobres (FREIRE, 1983; ROZEMBERG, 2007). Ainda Altieri (2012) reforça que a compartilhamento de tecnologias específicas para outros lugares e contextos pode fracassar, caso os solos, os implementos e a dimensão social forem desconsiderados.

Nesse contexto o objetivo deste estudo é realizar uma correspondência entre etnoconhecimento de agricultores familiares dos municípios de Morretes e Antonina/PR e o conhecimento científico pedológico. Para alcançar essa correspondência será utilizado o de levantamento de classes e atributos diagnósticos apresentados e utilizados pelos dois grupos estudados.

\section{MATERIAL E MÉTODOS}

\subsection{CARACTERIZAÇÃO DA ÁREA ESTUDADA}

Antonina e Morretes são municípios turísticos e agrícolas tradicionais do litoral do Paraná, se destacam pelas expressivas áreas destinadas á unidades de conservação e pelos extensos e contínuos remanescentes florestais da Mata Atlântica. Localizados no litoral do estado do Paraná (Figura 1), cujas sedes estão nas coordenadas $25^{\circ} 25^{\prime} 43^{\prime \prime} \mathrm{S}$ e $48^{\circ} 42^{\prime}$ ' $43^{\prime \prime} \mathrm{W}$; 2528' 37" S e 48 50' 04" W, possuem área de 876,5 e 687,5 km² e população censitária de 18.891 e 15.718 habitantes, respectivamente. (IPARDES, 2018).

Figura 1 - Localização dos municípios de Antonina e Morretes e das unidades de produção familiares

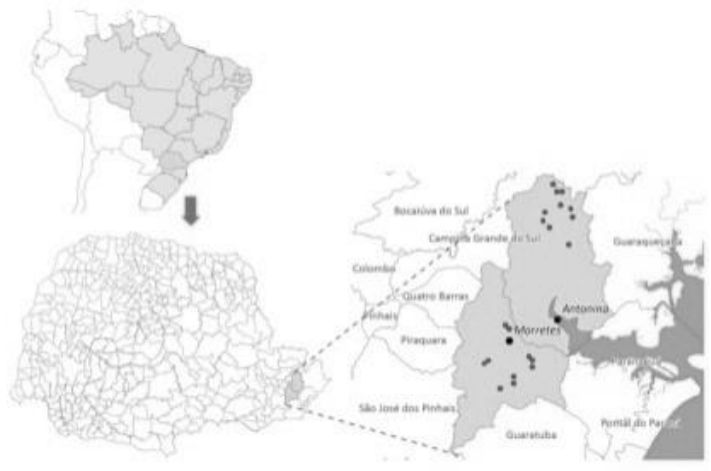

Fonte: IPARDES (2018) 
As propriedades agrícolas desses municípios possuem área média de 66 ha em Antonina e 25 ha em Morretes, e as principais atividades agropecuárias são os cultivos de banana, maracujá, palmito, tangerina, arroz, cana-de-açúcar, feijão, mandioca, milho, tomate e pequena criação de animais, como galinhas e bovinos (IPARDES, 2018).

O relevo da região se constitui por porções íngremes da Serra do Mar paranaense, recoberta por extensas áreas remanescentes do bioma Mata Atlântica, sendo a vegetação predominante Floresta Ombrófila Densa (IBGE, 2012). Nos pequenos gradientes altimétricos, a planície se apresenta como uma paisagem muito heterogênea e é constituída por depósitos marinhos, continentais e mistos e por morros isolados.

Entre os solos predominantes na planície destacam-se os Espodossolos Humilúvicos, constiuidos por sedimentos eólico-marinhos; os Gleissolos, em sedimentos continentais; e os Organossolos, todos encontrados em cotas geralmente inferiores a $50 \mathrm{~m}$. Em altimetrias superiores, em cadeias de elevação ou em morros e morrotes isolados, com cotas de até $240 \mathrm{~m}$ acima do nível do mar, podem ser encontrados com pouca expressividade os Latossolos, Argissolos e Cambissolos derivados dominantemente de rochas metamórficas - migmatitos, gnaisses ou xistos (BHERING; SANTOS, 2008).

\subsection{PESQUISA ETNOPEDOLÓGICA}

Participaram da pesquisa 20 famílias de agricultores (10 em cada município), totalizando o número de 103 pessoas. Os integrantes dessas famílias são de origem: nativas, totalmente imigrantes e mistas. Todas as unidades de produção são familiares e destas 18 utilizam o modelo de agricultura convencional e 02 orgânicas, os principais cultivos são maracujá, mandioca, chuchu, gengibre, olerícolas, banana, palmitos entre outras.

O critério de escolha, o número e as características dos entrevistados se baseou na metodologia de Geilfus (2002), segundo este autor, para a formação dos grupos de trabalho é necessário escolher as pessoas da comunidade com interesses comuns e que sejam voluntárias, ainda recomenda-se trabalhar em grupos pequenos, pois elevado número de participantes não permite tratar o tema com profundidade devido à heterogeneidade de opiniões.

As famílias entrevistadas no município de Antonina foram apresentadas pela coordenação do projeto de extensão universitária da Universidade Federal do Paraná - Setor Litoral "Feiras: sabores, memórias e identidades das comunidades de agricultores familiares do litoral paranaense". As famílias de Morretes foram apresentadas pelos técnicos do escritório local do Instituto Paranaense de Assistência Técnica e Extensão Rural (EMATER - PR).

O método de análise utilizado na pesquisa é o abdutivo, o qual se destaca pela interpretação e experiência de mundo social por seus membros. Assim, a tarefa do pesquisador é descobrir e descrever essa visão "de dentro" sem impor uma visão "de fora" (BLAIKIE, 2002).

O estudo etnopedológico foi conduzido através da metodologia de Geilfus (2002), de diagnóstico participativo, com adaptações, a qual possibilitou o trabalho direto no campo e se consistiu em quatro etapas: 1) Entrevistas narrativas com a família; 2) Elaboração de mapas participativos com a família; 3) Caminhadas na unidade de produção com os indivíduos da família; e 4) Reunião geral com os agricultores representantes das famílias.

As entrevistas foram conduzidas a partir de um guia, que é um conjunto de tópicos que "lembram" o pesquisador sobre os objetivos da sua pesquisa, criando 
um referencial confortável para uma discussão. As anotações foram registradas em uma caderneta de campo. Na entrevista narrativa, o objetivo é que o entrevistado relate livremente sobre o tema ou assunto abordado. A técnica tenta fugir do esquema pergunta-resposta, para conseguir uma versão menos imposta. A influência do pesquisador é mínima e se reduz a ouvir e manter o informante à vontade para narrar seus conhecimentos (PRUDENCIO, 2011).

A elaboração de mapas participativos teve por objetivo facilitar a visualização espacial das classes de terras descritas, e promover a condução das caminhadas pela unidade de produção que proporcionaram a visualização e conhecimento das terras. (GEILFUS, 2002).

Ao finalizar todas as etapas da pesquisa nas unidades de produção, foi realizada uma reunião geral, com oito representantes das famílias de agricultores de Antonina, o qual foi um momento importante para confirmar informações das entrevistas. Em Morretes não foi possível efetivar uma reunião geral devido a um desastre natural com fortes enxurradas e inundações bruscas, ocorrido em Março de 2011, impedindo a circulação pelo municipio prolongado tempo, conforme o decreto № 11/2011 (MORRETES, 2011).

Para averiguar as principais classes de terras e atributos referidos foi realizada a triangulação dos dados, que consistiu em conferir todas as informações obtidas nas entrevistas, mapas participativos, caminhadas e reunião geral, verificando a frequência de citações e assim construir uma tabela matriz com as classes identificadas (GEILFUS, 2002).

Para a análise da interpretação dos dados foi utilizada a técnica de análise da conversação e da fala. Este é um dos métodos da etnometodologia, que se interessa pela maneira como as pessoas se servem da linguagem para construir um conjunto de ações coordenadas e inteligíveis. Nessa técnica, ocorre análise de materiais orais que podem ser coletados por entrevistas. O pesquisador realiza uma análise detalhada com base na fala dos sujeitos da pesquisa, podendo, assim, identificar categorias utilizadas pelos participantes, como também, seus pontos de vista (MYERS, 2002).

Neste estudo os entrevistados não foram identificados para resguardar a privacidade das famílias.

\subsection{CLASSIFICAÇÃO CIENTÍFICA DE SOLOS}

Para a classificação cientifica dos solos foram empregadas as técnicas científicas formais pedológicas, utilizando dois perfis complementares de solo para cada classe etnopedológica identificada pelos agricultores, sendo um em cada município.

Para a descrição morfológica de solos foi utilizada a metodologia de Santos et al. (2005) e coletadas amostras que foram analisadas em relação a parâmetros químicos ( $\mathrm{pH}$ em $\mathrm{CaCl} 2, \mathrm{P}$ disponível, $\mathrm{Ca}, \mathrm{Mg}, \mathrm{K}$ e Al trocáveis, e acidez potencial) (MARQUES; MOTTA, 2003) e granulométricos (areia, silte e argila total pelo método do densímetro) (EMBRAPA, 2011).

Para enquadramento na classificação formal de solos tomou-se como referência o Sistema Brasileiro de Classificação de Solos (EMBRAPA, 2006).

\section{RESULTADOS E DISCUSSÃO}

Verificou-se que os agricultores entrevistados nomeiam as terras utilizando aspectos relacionados aos seus conhecimentos agrícolas da experiência diária, dos seus antepassados e das observações do ambiente natural. Por exemplo, ao 
denominar a classe "Terra de Morro" se emprega um parâmetro geomorfológico, pois associa a posição na paisagem e a fertilidade, para a terra "Sabão de Caboclo" serve-se de um aspecto histórico-cultural local, já a "Terra Argilosa" possui esse nome devido a sua textura e a "Terra de Desmonte" tem origem no conhecimento obtido dos fenômenos naturais (deposição de solo) observados ao longo tempo.

Em pesquisas anteriores observou-se que os agricultores pelo mundo utilizam essas mesmas variáveis para classificar os solos (OSUNADE, 1988; BRIGGS et al., 1998; QUEIROZ; NORTON, 1992; TALAWAR; RHOADES, 1998; ALVES et al., 2005; BENASSI et al., 2009; PALACIO; ARRIAGA, 2005; DAWOE et al., 2012; SIDERIUS; BAKKER, 2003; DAHMER, 2018).

Foram descritos dois perfis complementares de cada classe etnopedológica sendo um em cada município, cujas descrições morfológicas e análises laboratoriais constam nas tabelas 1 e 2 .

Tabela 1 - Caracterização morfológica dos perfis complementares descritos

\begin{tabular}{|c|c|c|c|c|c|c|c|}
\hline \multirow[b]{2}{*}{ Horizonte } & \multicolumn{7}{|c|}{ Consistência } \\
\hline & Prof. & Cor (úmida) & Estrutura & seca & úmida & molhada & textura \\
\hline \multicolumn{8}{|c|}{ Município de Antonina } \\
\hline \multicolumn{8}{|c|}{ "Terra de Morro" - CAMBISSOLO HÚMICO Distrófico típico, relevo ondulado. } \\
\hline A & $0-29$ & 7,5 YR $4 / 4$ & fo, me, bsa, & d & $\mathrm{fr}$ & Ipl e Ipe & Franco-argilosa \\
\hline$A B$ & $29-49$ & 7,5 YR $4 / 6$ & fo, gr, bsa & ld & $\mathrm{fr}$ & Ipl e pe & Franco-argilosa \\
\hline BA & $49-61$ & 5 YR $5 / 6$ & fo, me, bsa & Id & $\mathrm{fr}$ & Ipl e lpe & Franca \\
\hline $\mathrm{Bi}$ & $61-83$ & 5 YR 4/6 & fo, gr, bsa & d & $\mathrm{fr}$ & Ipl e npe & Franco-argilosa \\
\hline $\mathrm{C}$ & $83-123+$ & 5 YR 5/6 & mo, p, bsa & $\mathrm{mc}$ & $f$ & npl e npe & Franco-arenosa \\
\hline \multicolumn{8}{|c|}{ "Sabão de Caboclo" - GLEISSOLO HÁPLICO Tb Distrófico típico, relevo plano. } \\
\hline Ap & $0-20$ & 10 YR $2 / 1$ & $\mathrm{fr}, \mathrm{p}, \mathrm{bsa}$ & Id & $\mathrm{fr}$ & npl e lpe & Argiloarenosa \\
\hline $\mathrm{AB}_{\mathrm{b}}$ & $20-37$ & $2,5 \mathrm{YR} 4 / 2$ & fo, me, bsa & Id & $\mathrm{fr}$ & mpl e mpe & Argila \\
\hline $\mathrm{B}_{1} \mathrm{~g}$ & $37-52$ & 10 YR $5 / 1$ & fo, $m$ & d & $\mathrm{mf}$ & mpl e mpe & Argila \\
\hline $\mathrm{B}_{2} \mathrm{~g}$ & $52-60$ & 2,5 YR $6 / 1$ & fo, $m$ & d & $\mathrm{mf}$ & mpl e mpe & Argila \\
\hline \multirow{2}{*}{\multicolumn{8}{|c|}{ "Terra Argilosa" - CAMBISSOLO HÁPLICO Tb Distófico típico, relevo suave ondulado. }} \\
\hline & & & & & & & \\
\hline$A$ & $0-25$ & 10 YR 4/3 & $\mathrm{mo}, \mathrm{p}, \mathrm{bsa}$ & Id & $f$ & mpl e pe & Argila \\
\hline$A B$ & $25-35$ & 10 YR $7 / 4$ & fo, me, bsa & Id & $f$ & mpl e pe & Argilosiltosa \\
\hline $\mathrm{Bi}$ & $35-55$ & 10 YR $7 / 6$ & fo, gr, bsa & Id & $f$ & npl e lpe & Argilosiltosa \\
\hline $\mathrm{BC}$ & $55-70$ & 10 YR $7 / 6$ & mo, gr, bsa & Id & $\mathrm{fr}$ & npl e npe & Franco-siltosa \\
\hline $\mathrm{C}$ & $70-100^{+}$ & 10 YR $8 / 4$ & mo, gr, bsa & Id & $f$ & npl e npe & Silte \\
\hline \multicolumn{8}{|c|}{ “Terra de Desmonte” - CAMBISSOLO FLÚVICO Ta Distrófico típico, relevo plano. } \\
\hline Ap & $0-10$ & 10YR $4 / 4$ & mo, me, bsa & Id & f & Ip e pe & Franco-argilosa \\
\hline $\mathrm{Bi}$ & $10-37$ & $10 Y R 4 / 3$ & mo, gr, bsa & Id & $\mathrm{mfr}$ & npl e npe & Franco-arenosa \\
\hline $2 \mathrm{C}$ & $37-82$ & 10YR 4/6 & mo, gr, bsa & Id & $\mathrm{mfr}$ & npl e npe & Franco-argilo-siltosa \\
\hline \multicolumn{8}{|c|}{ Município de Morretes } \\
\hline \multicolumn{8}{|c|}{ "Terra de Morro" - ARGISSOLO VERMELHO-AMARELO Distrófico típico, relevo ondulado. } \\
\hline A & $0-20$ & $10 \mathrm{YR} 4 / 4$ & fr, gra, gr & $\mathrm{s}$ & f & npl e npe & Argiloarenosa \\
\hline Bt & $20-100+$ & 10YR $6 / 6$ & mo, gr, ba & ed & $\mathrm{mfr}$ & pl e npe & Muito argilosa \\
\hline \multicolumn{8}{|c|}{ "Sabão de Caboclo" - GLEISSOLO HÁPLICO Ta Eutrófico típico, relevo plano. } \\
\hline Ap & $0-25$ & 2,5 YR $4 / 3$ & fo,gr, bsa & d & $\mathrm{fr}$ & Ipl e npe & Franco-argilosa \\
\hline $\mathrm{Bg}$ & $25-55$ & $2,5 Y R 6 / 4$ & mo, me, bsa & $\mathrm{d}$ & $\mathrm{fr}$ & mpl e pe & Franco-argilosa \\
\hline & $55-125$ & $5 Y 7 / 2$ & Fo, $\mathrm{m}$ & ed & $\mathrm{mf}$ & npl e npe & Argila \\
\hline \multicolumn{8}{|c|}{ "Terra Argilosa" - CAMBISSOLO HÁPLICO Ta Eutrófico típico, relevo plano. } \\
\hline Ap & $0-30$ & 10YR $4 / 6$ & mo, gr, bsa, & d & f & pl e npe & Argila \\
\hline $\mathrm{Bi}$ & $30-120+$ & 10YR 5/6 & mo, gr, bsa & d & f & Ipl e npe & Argilosiltosa \\
\hline \multicolumn{8}{|c|}{ "Terra de Desmonte" -NEOSSOLO FLÚVICO Ta Eutrófico típico, relevo plano. } \\
\hline Ap & $0-20$ & 10YR $4 / 4$ & $\mathrm{f}, \mathrm{me}, \mathrm{bsa}$ & $\mathrm{mc}$ & $\mathrm{mf}$ & npl e npe & Argiloarenosa \\
\hline $2 \mathrm{C}$ & $20-40$ & $10 Y R 4 / 3$ & $f, p, b s a$ & $\mathrm{~s}$ & s & npl e npe & Franco-arenosa \\
\hline $3 \mathrm{C}$ & $40-85+$ & 10YR 4/6 & mo, gr, bsa & $\mathrm{mc}$ & $\mathrm{mf}$ & Ipl e npe & Argila \\
\hline \multicolumn{8}{|c|}{$\begin{array}{l}\text { Similar à estratificação dos sedimentos. f: fraca; mo: moderada; me: media; fo: forte; p: pequena; gr: grande; m: maciça; pr } \\
\text { prismática; ba: blocos angulares; bsa: blocos subangulares; gra: granular; gs: grão simples; s: solta; mc: macia; Id: ligeiramente } \\
\text { dura; d: dura; md: muito dura; ed: extremamente dura; mfr: muito friável; f: friável; fr: firme; mf: muito firme; npl: não plástica; Ipl } \\
\text { ligeiramente plástica; pl: plástica; mpl: muito plástica; npe: não pegajosa; Ipe: ligeiramente pegajosa; pe: pegajosa; mpe: muito } \\
\text { pegajosa. } \\
\text { Fonte: Tavares e Lima (2012) }\end{array}$} \\
\hline
\end{tabular}


Tabela 2 - Caracterização química e física dos perfis complementares descritos

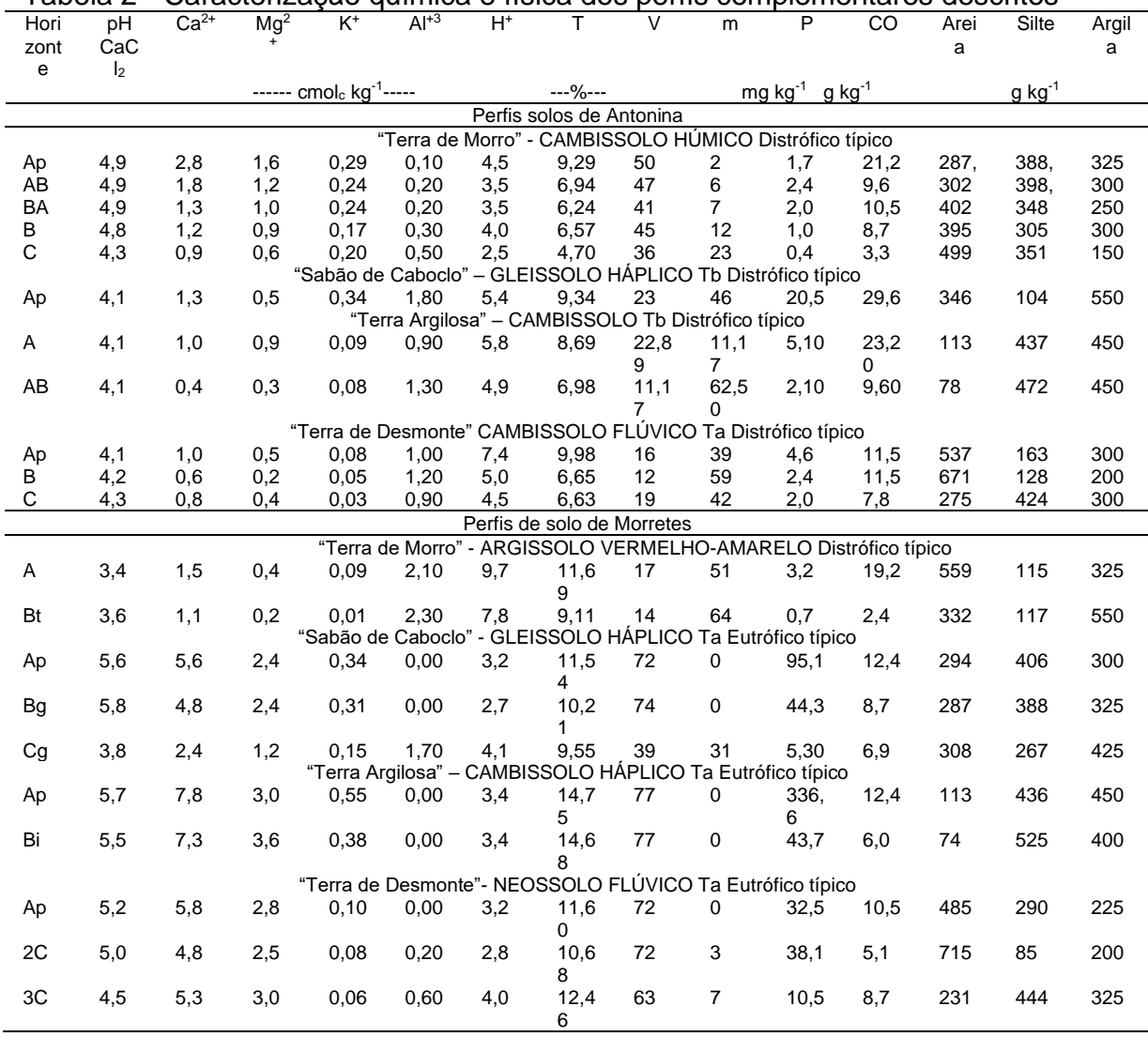

$\mathrm{T}$ = capacidade de troca de cátions a $\mathrm{pH} 7,0 ; \mathrm{V}=$ saturação de bases; $\mathrm{m}$ = saturação de alumínio; $\mathrm{CO}$ = carbono orgânico; $\mathrm{P}$ = fósforo disponível extraído por Mehlich-1.

Fonte: Tavares e Lima

Logo o sistema científico utiliza as características predominantes nas classes como aspectos relacionados à gênese do solo no caso dos Neossolos ou em características físicas como nos Vertissolos, Latossolos e Plintossolos. Os nomes dos solos, no sistema científico, também consideram aspectos históricoculturais como no caso dos Gleissolos e Chernossolos que são baseados nos conhecimentos locais de agricultores russos, e que foram adotados em diversos sistemas de classificação do mundo e tem origem nos estudos de Vasily Vasili'evich Dokuchaev datados a partir de 1877 (KRASILNIKOV; TABOR, 2003).

Neste estudo não foram identificados níveis hierárquicos na classificação etnopedológica, a nomenclatura atribuída se utiliza somente de termos compostos para designar as terras como "Terra de Desmonte" ou "Sabão de Caboclo", já a classificação formal de solos possui níveis hierárquicos, e apresenta maiores especificidades nas características consideradas.

Constatou-se que as terras classificadas pelos agricultores entrevistados apresentam diferenças e não correspondem sempre à mesma classe de solo conforme o SiBCS. É o caso da "Terra de Morro" e da "Terra de Desmonte" que apresentaram mais de uma ordem correspondente no SiBCS. Porém outras classes 
etnopedológicas apresentaram uma única subordem no SiBCS, como no caso do "Sabão de Caboclo" e "Terra Argilosa" (Quadro 1).

Quadro 1 - Classificação etnopedológica e respectiva classificação formal do SiBCS

\begin{tabular}{|l|l|}
\hline Classe etnopedológica & Classificação formal \\
\hline \multirow{3}{*}{ "Terra de Morro" } & ARGISSOLO VERMELHO-AMARELO Distrófico típico \\
\cline { 2 - 2 } & CAMBISSOLO HÚMICO Distrófico típico \\
\hline \multirow{3}{*}{ "Terra Argilosa" } & GLEISSOLO HÁPLICO Tb Distrófico típico \\
\cline { 2 - 2 } & GLEISSOLO HÁPLICO Ta Eutrófico típico \\
\hline \multirow{2}{*}{ "Terra de Desmonte" } & CAMBISSOLO HÁPLICO Tb Distrófico típico \\
\cline { 2 - 2 } & CAMBISSOLO HÁPLICO Ta Eutrófico típico \\
\hline & CAMBISSOLO FLÚVICO Ta Distrófico típico \\
\cline { 2 - 2 } & NEOSSOLO FLÚVICO Ta Eutrófico típico \\
\hline
\end{tabular}

Fonte: Tavares Lima (2012)

Resultados semelhantes foram descritos por Queiroz e Norton (1992) em uma pesquisa etnopedológica com agricultores cearenses do Vale do rio Acaraú, na qual foram encontradas classificações locais que nem sempre correspondiam à mesma categoria de solo, ainda os autores concluíram que as classificações locais representam a forma como as pessoas percebem o ambiente e que o conhecimento não deve ser ampliado de qualquer maneira para outros locais.

Em uma revisão de literatura realizada por Oudwater e Martin (2003) sobre as metodologias e particularidades nas pesquisas etnopedológicas, foi verificado que os agricultores realizam suas observações de forma qualitativa e que as percepções podem variar de um entrevistado para outro, ressaltando a premissa de que o conhecimento é local e específico e por isso não pode ser generalizado.

Ainda sobre análises comparativas sobre classes de solo de agricultores e cientistas Talawar e Rhoades (1998) observaram que o conhecimento local é altamente contextual e pode ter relação com os atributos, propriedades ou uso do solo. Através de um estudo documental bibliográfico Sillitoe (1998) constatou que as comparações entre classificações locais e científicas são complexas porque elas possuem critérios diferentes de avaliação e o conhecimento etnopedológico é específico para o local e culturalmente relativo, enquanto o conhecimento científico é amplo no sentido de que é contemplado por todos os cientistas de solo e voltado para uma perspectiva global.

Se ressalta que o SiBCS foi concebido para classificar os solos em nível nacional e, portanto, os critérios de separação apresentam limites que, muitas vezes, podem distinguir solos muito semelhantes entre si, mas que apresentam tendência para o conceito central de suas respectivas classes taxonômicas. Essa pode ser uma explicação para a variação de classes formais diante das classes etnopedologicas encontradas nesta pesquisa.

Contudo, em uma investigação com agricultores do sudoeste da Nigéria, Osunade (1988) constatou que uma classe formal de solo pode ser constituída por mais de uma classe etnopedológica, indicando que os agricultores também podem refinar aspectos não contemplados em classificações taxonômicas. No caso dos agricultores de Morretes e Antonina essa variação ocorreu na "Terra de Morro" a qual apresentou duas classes distintas para a mesma classe etnopedológica. 
Pode ainda ocorrer uma baixa correlação entre os sistemas etnopedológicos e científicos de classificação, conforme foi observado por Braimoh (2002) em uma pesquisa realizada com agricultores e populações tradicionais da Nigéria. Também Ali (2003), em uma pesquisa com agricultores do sul de Bangladesh, verificou que a classificação etnopedológica diferiu da científica, devido aos diferentes objetivos e abordagens realizadas por agricultores e cientistas.

Resultados semelhantes foram descritos por Queiroz e Norton (1992) em uma pesquisa etnopedológica com agricultores cearenses do Vale do rio Acaraú, na qual foram encontradas classificações locais que nem sempre correspondiam à mesma categoria de solo. Os autores concluíram que as classificações locais representam a forma como as pessoas percebem 0 ambiente e que estas observações indicam que a relação do conhecimento etnopedológico e as características de solo devem ser verificadas localmente.

Em uma revisão de literatura realizada por Oudwater e Martin (2003) sobre as metodologias e particularidades nas pesquisas etnopedológicas, foi verificado que os agricultores realizam suas observações de forma qualitativa e que as percepções podem variar de um entrevistado para outro, ressaltando a premissa de que o conhecimento é local e específico e por isso não pode ser generalizado.

Ainda sobre análises comparativas sobre classes de solo de agricultores e cientistas Talawar e Rhoades (1998) observaram que o conhecimento local é altamente contextual e pode ter relação com os atributos, propriedades ou uso do solo.

Através de um estudo documental bibliográfico Sillitoe (1998) constatou que as comparações entre classificações locais e científicas são complexas porque elas possuem critérios diferentes de avaliação e o conhecimento etnopedológico é específico para o local e culturalmente relativo, enquanto o conhecimento científico é amplo no sentido de que é contemplado por todos os cientistas de solo e voltado para uma perspectiva global.

Se ressalta que o SiBCS foi concebido para classificar os solos em nível nacional e, portanto, os critérios de separação apresentam limites que, muitas vezes, podem distinguir solos muito semelhantes entre si, mas que apresentam tendência para o conceito central de suas respectivas classes taxonômicas. Essa pode ser uma explicação para a variação de classes formais diante das classes etnopedológicas encontradas nesta pesquisa.

Contudo, em uma investigação com agricultores do sudoeste da Nigéria, Osunade (1988) constatou que uma classe formal de solo pode ser constituída por mais de uma classe etnopedológica, indicando que os agricultores também podem refinar aspectos não contemplados em classificações taxonômicas. No caso dos agricultores de Morretes e Antonina essa variação ocorreu na "Terra de Morro" a qual apresentou duas classes distintas para a mesma classe etnopedológica.

Pode ainda ocorrer uma baixa correlação entre os sistemas etnopedológicos e científicos de classificação, conforme foi observado por Braimoh (2002) em uma pesquisa realizada com agricultores e populações tradicionais da Nigéria. Também Ali (2003), em uma pesquisa com agricultores do sul de Bangladesh, verificou que a classificação etnopedológica diferiu da científica, devido aos diferentes objetivos e abordagens realizadas por agricultores e cientistas.

Diante desse cenário, a seguir serão apresentadas a principais classes mencionadas pelos agricultores entrevistados e suas relaçõeses como Sistema Brasileiro de Classificação de Solos. 


\subsection{CLASSES E ATRIBUTOS OBSERVADOS POR AGRICULTORES E CIENTISTAS}

\subsection{1. "TERRA DE MORRO"}

A classe etnopedológica "Terra de Morro" correspondeu no SiBCS às classes dos Argissolos e Cambissolos (figura 2). Ao comparar as duas classificações, local e a formal, foi encontrada similaridade entre 0 atributo fertilidade enquanto os atributos textura e cor apresentaram variações e diferenças.

Figura 2. Perfis correspondentes à classe etnopedológica "Terra de Morro" em Antonina (esquerda) e Morretes (direita)

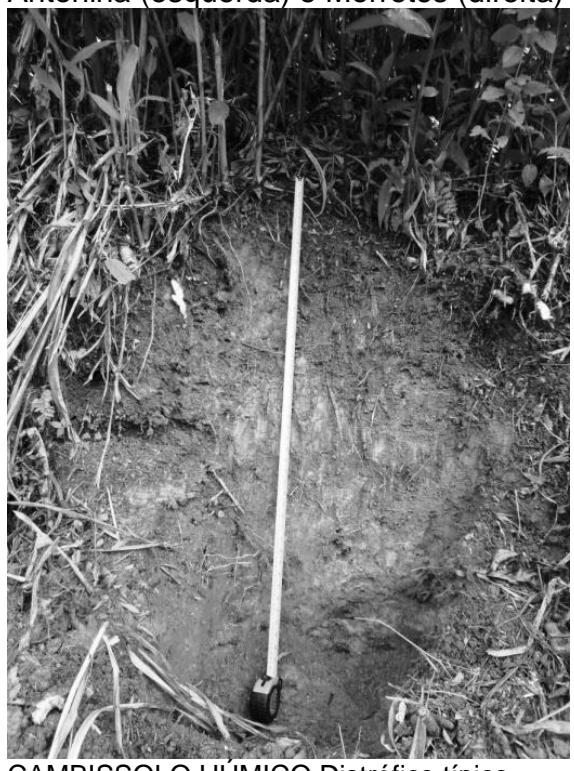

CAMBISSOLO HUMICO Distrófico típico

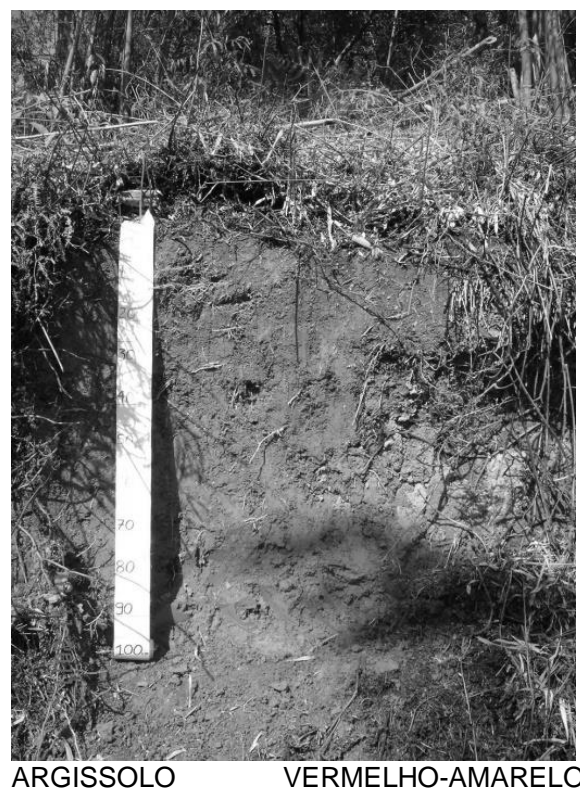

Distrófico típico

Fonte: Tavares e Lima (2012)

Para os agricultores entrevistados a "Terra de Morro" é considerada como "fraca" expressando que esta apresenta baixa fertilidade natural. Este aspecto também foi encontrado nos dois perfis descritos que apresentaram caráter distrófico.

A cor é um atributo que teve variação entre os agricultores entrevistados, pois alguns relataram que a "Terra de Morro" possui cor "preta", enquanto outros mencionam a cor "avermelhada". Para o SiBCS os Argissolos e Cambissolos também podem apresentar variações de cores, e o atributo cor é utilizado para o enquadramento de classes em níveis categóricos mais baixos. Em relação à cor também deve ser ressaltado que os agricultores geralmente consideram a parte mais superficial do solo ("camada arável"), a qual pode estar inclusive erodida, em função do relevo, com a ocorrência do horizonte BA, Bt ou Bi truncado na superfície.

A textura relatada pelos entrevistados é "intermediária" ou "meio a meio, meio argilosa meio arenosa", sendo este aspecto confirmado em múltiplos relatos. A diferença nas percepções dos agricultores relacionadas à textura também pode estar associada ao gradiente textural que pode existir entre os horizontes 
superficiais e subsuperficiais dos Argissolos (EMBRAPA, 2006). Em síntese, os atributos cor e textura foram descritos de forma genérica na classificação etnopedológica.

Para que uma classe de terra possa ser considerada pelos agricultores como "Terra de Morro" não é necessário apresentar sempre a mesma cor ou textura, bastando estar localizada em uma encosta íngreme para ser categorizada como "Terra de Morro". No caso desta classe, a metodologia não pode perceber maior detalhamento da classificação etnopedológica, o que também pode estar associado à menor utilização destas áreas pelos agricultores, devido relevo.

\subsection{2. "SABÃO DE CABOCLO".}

A classe etnopedológica "Sabão de Caboclo" correspondeu no SiBCS a Gleissolos (figura 3), bem como as classificações local e formal, apresentaram semelhanças específicas entre os atributos cor, estrutura, drenagem e textura.

Figura 3. Perfis correspondentes à classe etnopedológica "Sabão de Caboclo" em Antonina (esquerda) e Morretes (direita)

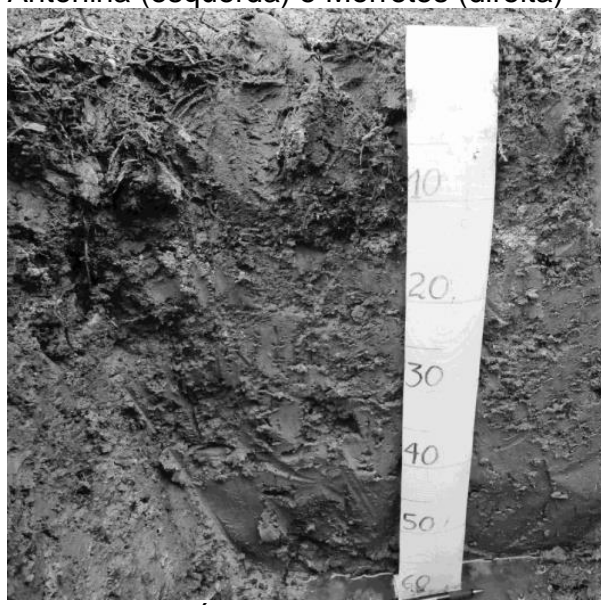

GLEISSOLO HÁPLICO Tb Distrófico típico Fonte: Tavares e Lima (2012)

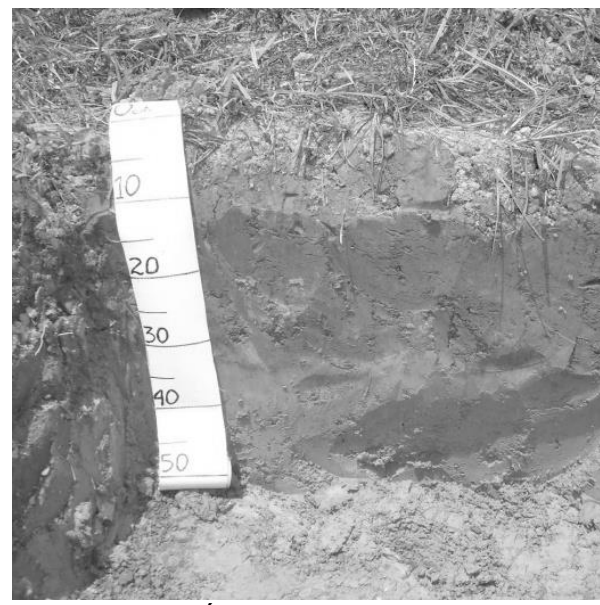

GLEISSOLO HÁPLICO Ta Eutrófico típico

A cor foi um atributo determinante para essa classe etnopedológica, que foi nomeada de "branca" ou "esbranquiçada" por vários agricultores entrevistados. Os Gleissolos caracterizam-se pela forte gleização, em decorrência do ambiente redutor, e este processo tem como consequência a manifestação de cores acinzentadas, azuladas ou esverdeadas, devido à redução e solubilização do ferro, permitindo a expressão de cores neutras dos argilominerais (EMBRAPA, 2006).

A restrição de drenagem é um atributo determinante na classificação etnopedológica e, de modo semelhante, o SiBCS também explana que os Gleissolos encontram-se permanentemente ou periodicamente saturados por água. Relatos demonstram que os agricultores percebem que a água pode se elevar no solo conforme o comentário "Quando a gente vai passar a Tobata, a gente percebe que tem água até em cima dos morros, a gente brinca que a água subiu". O entrevistado refere-se à ascensão capilar da água, característica também descrita no SiBCS para os Gleissolos. 
O SiBCS descreve a estrutura do horizonte $\mathrm{C}$ como em geral maciça, atributo observado também pelos agricultores, pois na nomenclatura etnopedológica "Sabão de Caboclo" tem procedência dessa estrutura maciça que lembra uma pedra (bloco) "sabão" caseiro. Deve-se destacar que o termo Gleissolo é derivado do russo "massa pastosa" (ANJOS et al., 2012).

\subsection{3. "TERRA ARGILOSA"}

A classe etnopedológica "Terra Argilosa" correspondeu no SiBCS aos Cambissolos de relevo plano (figura 4), e os atributos comuns entre as duas classificações foram cor, textura e fertilidade. Um atributo somente citado na classificação etnopedológica foi a capacidade de reter água.

Figura 4. Perfis correspondentes à classe etnopedológica "Terra Argilosa" em Antonina (esquerda) e Morretes (direita)

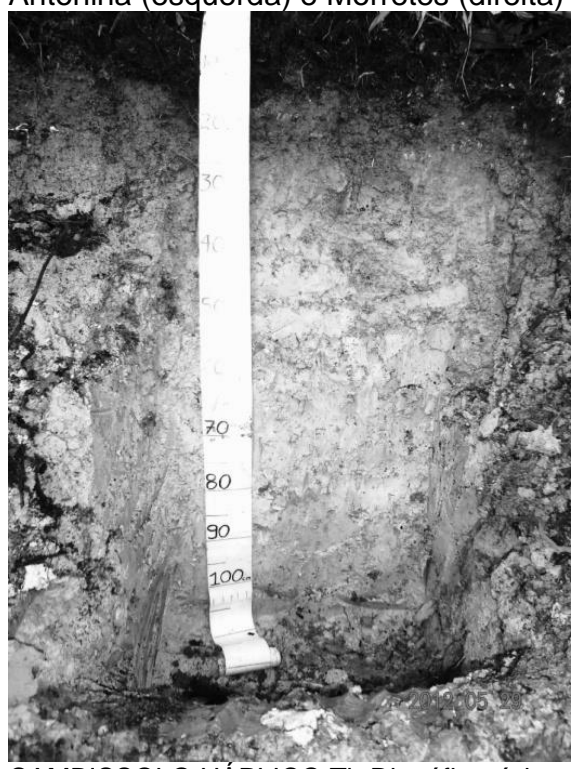

CAMBISSOLO HÁPLICO Tb Distrófico típico Fonte: Tavares e Lima (2012)

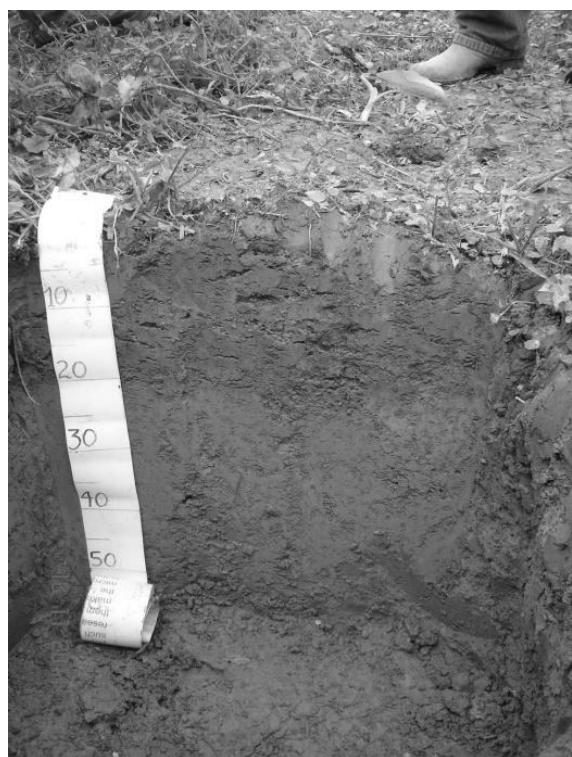

CAMBISSOLO HÁPLICO Ta Eutrófico típico

A cor relatada pelos agricultores entrevistados foi "avermelhada" ou "vermelha", "marrom" ou "amarela" ou "amarelada", no SiBCS a cor também é considerada para a classificação, porém com maior variação no caso dos Cambissolos. Deve-se considerar, no entanto, que a cor é um atributo subjetivo podendo variar entre os observadores, até mesmo na ciência formal, que utiliza padrões como a Carta de Munsell.

A textura descrita pelos agricultores entrevistados é "argilosa", isto é, que possui maior quantidade de argila do que areia. A classe textural dos Cambissolos descritos é argilosa, concordando com a percepção dos agricultores. A fertilidade da "Terra Argilosa" é considerada boa conforme os relatos dos agricultores e, segundo a classificação do SiBCS, este solo é distrófico em Antonina e eutrófico em Morretes, demonstrando que os agricultores não observam somente parâmetros químicos para definir a fertilidade de uma terra mas relacionam este conceito a 
outros fatores como textura, posição na paisagem, cor entre outros. Resultados semelhantes foram observados em outras pesquisas etnopedológicas (Briggs et al., 1998; Siderius; Bakker, 2003; Mairura et al., 2007; Lima et al., 2011; Dawoe et al., 2012).

Os agricultores entrevistados percebem que esta terra em períodos de estiagem consegue reter água, a qual permanece disponível por períodos prolongados para as plantas. Esta característica remete aos conceitos de ponto de murcha permanente e capacidade de campo, comumente utilizado por cientistas do solo. Agricultores de Honduras também mencionam a capacidade de alguns solos reterem água em épocas de estiagem como uma característica importante para os cultivos (Ericksen; Ardón, 2003).

\subsection{4. "TERRA DE DESMONTE"}

A classe etnopedológica "Terra de Desmonte" correspondeu no SiBCS aos Neossolos Flúvicos e Cambissolos Flúvicos (figura 5), e os atributos diagnósticos comuns entre as duas classificações foram textura, drenagem, matéria orgânica, fertilidade, e caráter flúvico ou influência dos rios.

Figura 5. Perfis correspondentes à classe etnopedológica "Terra de Desmonte" em Antonina (esquerda) e Morretes (direita)

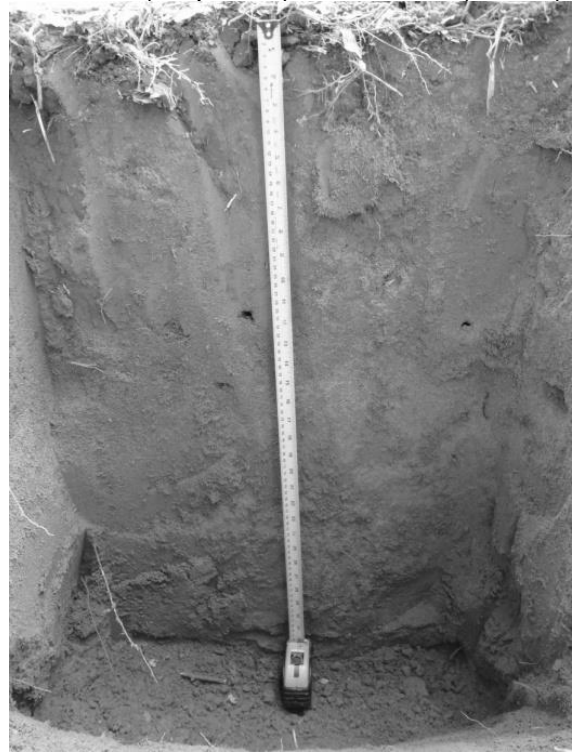

CAMBISSOLO FLÚVICO Ta Distrófico típico Fonte: Tavares e Lima (2012)

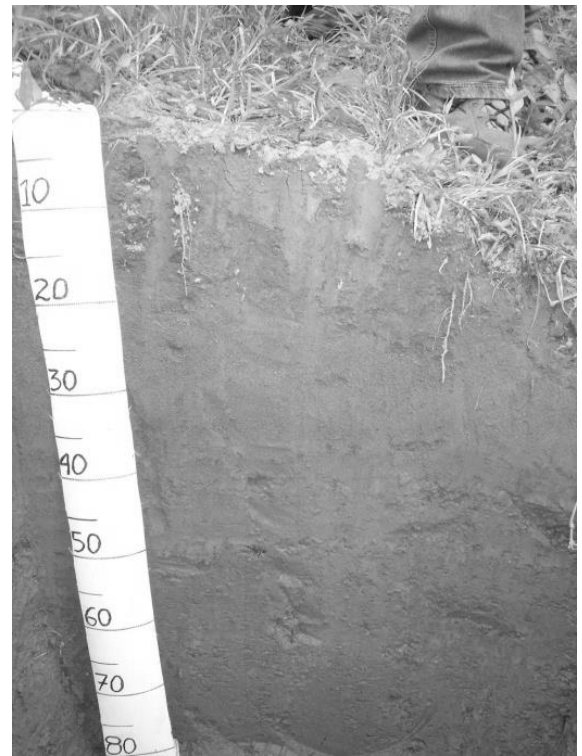

NEOSSOLO FLÚVICO Ta Eutrófico típico

A textura da "Terra de Desmonte" relatada pelos agricultores entrevistados é "arenosa", enquanto os solos descritos se situaram no grupamento textural médio (francoargilosa, argiloarenosa, franco-arenosa, franco-argilo-siltosa) (TABELA 6). Embora os solos não sejam formalmente classificados como arenosos, não se pode deixar de relatar a maior presença de areia em relação a outros solos encontrados nas áreas agrícolas de Antonina e Morretes. Também poderia ser considerado o fato de que os Espodossolos, existentes nestes municípios, apresentam maiores teores 
de areia, contudo tem pequena expressão geográfica e, normalmente, não apresentam uso agrícola.

A matéria orgânica foi mencionada, na classificação etnopedológica, como um atributo importante para a fertilidade. Na ciência formal também se considera o teor de carbono orgânico para classificar os solos, como no caso dos Neossolos Flúvicos e Cambissolos Flúvicos nos quais pode ocorrer a distribuição irregular do conteúdo de carbono orgânico em profundidade. A fertilidade foi relatada pelos agricultores entrevistados como ótima, pois, segundo eles, estas terras, em épocas de enchentes, são cobertas pelas águas dos rios que depositam nutrientes contribuindo para boas produções agrícolas. Também é relatada como parte da vocação da "Terra de Desmonte" a combinação das características que ela possui como boa drenagem. A fertilidade para esses agricultores não depende somente dos nutrientes do solo, mas também de outros fatores que possam promover a produção agrícola como boa drenagem e relevo plano. Para a classificação formal esses solos foram considerados como eutróficos para o Neossolo, concordando com a opinião dos entrevistados.

Foi relatada tanto pela classificação etnopedológica quanto a do SiBCS a influência dos rios na formação do solo ou como é denominado pela ciência formal de caráter flúvico, que está relacionado à influência de sedimentos de natureza aluvionar na pedogênese.

\subsection{ATRIBUTOS DIAGNÓSTICOS ETNOPEDOLÓGICOS E DA CIÊNCIA FORMAL}

A classificação realizada pelos agricultores entrevistados é baseada principalmente em características morfológicas que podem ser designados como atributos diagnósticos conforme éverificado no (Quadro 2).

Quadro 2 - Atributos diagnósticos utilizados para classificação etnopedológica e formal (Sistema Brasileiro de Classificação de Solos - SiBCS).

\begin{tabular}{|c|c|c|c|}
\hline $\begin{array}{l}\text { Classe } \\
\text { etnopedológica }\end{array}$ & Principais atributos & Classe SiBCS & Principais atributos \\
\hline $\begin{array}{l}\text { "Terra de } \\
\text { Morro" }\end{array}$ & $\begin{array}{l}\text { Cor, textura, fertilidade, } \\
\text { Posição na paisagem. }\end{array}$ & $\begin{array}{l}\text { ARGISSOLOS } \\
\text { CAMBISSOLOS }\end{array}$ & $\begin{array}{lr}\text { Cor, } & \text { textura, } \\
\text { fertilidade, } & \text { material } \\
\text { mineral. } & \\
\end{array}$ \\
\hline $\begin{array}{l}\text { "Sabão } \\
\text { Caboclo" }\end{array}$ & $\begin{array}{l}\text { Cor, textura, drenagem } \\
\text { consistência, posição } \\
\text { na paisagem. }\end{array}$ & GLEISSOLOS & $\begin{array}{l}\text { Cor, } \\
\text { drenagem, textura, } \\
\text { mineral. }\end{array}$ \\
\hline $\begin{array}{l}\text { "Terra } \\
\text { Argilosa" }\end{array}$ & $\begin{array}{l}\text { Cor, textura, fertilidade, } \\
\text { retenção de água, } \\
\text { posição na paisagem. }\end{array}$ & CAMBISSOLOS & $\begin{array}{l}\text { Cor, } \\
\text { fertilidade, } \\
\text { mineral. }\end{array}$ \\
\hline $\begin{array}{ll}\text { "Terra de } \\
\text { Desmonte" }\end{array}$ & $\begin{array}{l}\text { Textura, fertilidade, } \\
\text { matéria orgânica, } \\
\text { influência do rio, } \\
\text { posição na paisagem. }\end{array}$ & $\begin{array}{l}\text { NEOSSOLOS } \\
\text { CAMBISSOLOS }\end{array}$ & $\begin{array}{l}\text { Textura, fertilidade, } \\
\text { carbono orgânico, } \\
\text { caráter flúvico, cor, } \\
\text { material mineral. }\end{array}$ \\
\hline
\end{tabular}

Fonte: Tavares e Lima (2012)

O conhecimento local baseia-se na combinação destes atributos para determinar as classes de terra. A "Terra de Morro", por exemplo, tem essa 
denominação por que está localizada em áreas de encosta com declives acentuados em média de $20 \%$ a $45 \%$, baixa fertilidade, textura "intermediária" conforme o relato de um agricultor.

$\mathrm{Na}$ ciência formal, nos sistemas de classificação de solos, também empregam atributos diagnósticos para descrever e categorizar. Em geral os atributos diagnósticos semelhantes nas classes etnopedológicas e no sistema formal foram cor, textura e fertilidade. Os atributos diagnósticos que não são comuns entre os dois sistemas foram posição na paisagem para a classificação etnopedológica e para o SiBCS foi o material mineral. Os atributos diagnósticos relatados pelos agricultores são comuns mesmo para as diferentes classes de solo enquadradas no SiBCS.

A ciência formal também associa diversos atributos para classificar o solo e considera os processos de formação do solo, fator não percebido pelos entrevistados (SILLITOE, 1998; TALAWAR; RHOADES, 1998; BRAIMOH, 2002; ALI, 2003). Vale ressaltar que estas classificações, a etnopedológica e a científica, possuem objetivos diferentes. Enquanto a primeira preocupa-se com uso agrícola do solo sendo uma classificação técnica e local utilizada por esses agricultores, a ciência formal baseia-se em uma classificação taxonômica que pode ser utilizada para variadas finalidades por diversos profissionais. Resultados semelhantes foram verificados em outras pesquisas etnopedológicas (OSUNADE, 1988; TALAWAR; RHOADES, 1998; BRAIMOH, 2002; ERICKSEN; ARDÓN, 2003).

\section{CONSIDERAÇÕES FINAIS}

Determinadas classes etnopedológicas tiveram correlações positivas com as classes do SiBCS como o "Sabão de caboclo" e GLEISSOLOS, a "Terra Argilosa" e CAMBISSOLOS, A "Terra de Desmonte" teve adjacência com o caráter flúvico das classes formais obtidas. A classificação etnopedológica e a classificação do SiBCS apresentaram semelhanças sendo que vários atributos são comuns às percepções dos dois grupos avaliadores.

Os atributos diagnósticos frequentemente utilizados pelos agricultores e pelo SiBCS foram cor, textura e fertilidade. Os atributos diagnósticos incoomuns entre as classificações foram posição na paisagem para a etnopedológica e para o SiBCS foi o material mineral.

A pesquisa indica que o conhecimento etnopedológico está presente nas comunidades participantes dessa pesquisa e que apresentam muitas conexões com o conhecimento cientifico pedológico. Os resultados obtidos podem ser empregados em pesquisas, atividades de ensino, extensão e produção de materiais didáticos dessa forma contribui para uma integração dos conhecimentos locais e científicos. Almeja-se que este estudo seja contribuinte para uma ciência um pouco mais democrática e aproximada da realidade das comunidades.

\section{AGRADECIMENTOS}

Agradeço a todos os agricultores, agricultoras, jovens, crianças e idosos que dedicaram seu tempo, atenção e conhecimentos para a realização deste trabalho. 


\section{REFERÊNCIAS}

ALI, A.M.S. Farmers' knowledge of soils and the sustainability of agriculture in a saline water ecosystem in Southwestern Bangladesh. Geoderma, v.111, p.333-353, 2003.

ALIER, J.M. O ecologismo dos pobres: conflitos ambientais a linguagens de valoração. São Paulo: Contexto, 2014.

ALTIERI, M. Agroecologia: bases científicas para uma agricultura sustentável. São Paulo: Expressão Popular, 2012.

ALVES, A.G.C.; MARQUES J.G.W.; QUEIROZ S.B.; SILVA, I.F.; RIBEIRO M.R. Caracterização etnopedológica de Planossolos utilizados em cerâmica artesanal no agreste paraibano. Revista Brasileira de Ciência do Solo, v.29, p. 379-388, 2005.

ALVES, A.G.C; RIBEIRO, M.R.; ANJOS L.H.C.; CORREIA, J.R. Por que estudar os nomes dados aos solos pelos camponeses? 2006. 56 p. (Boletim Informativo da Sociedade Brasileira de Ciência do Solo 31).

ANJOS, L.H.C; JACOMINE, P.K; SANTOS, H.G.; OLIVEIRA, V.A.; OLIVEIRA, J.B. Sistema Brasileiro de Classificação de Solos. In: KER, J.C.; CURI, N.; SCHAEFER, C.E.G.R.; VIDAL-TORRADO, P. (Eds.). Pedologia: fundamentos. Viçosa, Sociedade Brasileira de Ciência do Solo, 2012.

ARAÚJO, A.L.; ALVES, A.G.C.; ROMERO, R.E.; FERREIRA, T.O. Etnopedologia: uma abordagem das etnociências sobre as relações entre as sociedades e os solos. Ciência Rural. v.43, n.5, p.854-860, 2013.

BARRERA-BASSOLS, N. Etnoedafología Purépecha: conocimiento y uso de los suelos en la cuenca de Pátzcuaro. México Indígena, v.24, p.47-52, 1988.

NETO; MARQUES; NASCIMENTO; BARROS; VODZIK; MENEZES; LIMA. Entre "solos" e "terras": Etnopedologia, assentamentos rurais e processos participativos. Sociedade \& Natureza. v.3. p. 1-1. 2019.

BENASSI, D.A.; SANTOS, J.A.B.; GIAROLA, N.F.B. Conhecimentos etnopedológicos dos agricultores do centro-sul do Paraná. Revista Brasileira de Agroecologia, v. 4, n. 2, p. 1862-1865, 2009.

MYERS, G. Análise da conversação e da fala. In: BAUER, M.W.; GASKELL, G. Pesquisa qualitativa com texto, imagem e som. um manual prático. Petrópolis, Vozes, 2002. p. 270-278.

BHERING, S.B.; SANTOS, H.G. (Eds.). Mapa de solos do estado do Paraná: legenda atualizada. Rio de Janeiro: Embrapa Solos, 2008.

BLAIKIE, N.W.H. Designing social research: the logic of anticipation. London: Polity Press, 2002. 
BRAIMOH, A.K. Integrating indigenous knowledge and soil science to develop a national soil classification system for Nigeria. Agriculture and Human Values, v.19, p 75-80, 2002.

BRIGGS, J.; PULFORD, I.D.; BADRI, M.; SHAHEEN, A.S. Indigenous and scientific knowledge: the choice and management of cultivation sites by bedouin in Upper Egypt. Soil Use and Management, v. 14, n. 4, p. 240-245, 1998.

CARVALHO, J.W.C. Diálogos entre agroecologia e etnopedologia: sítio Tapera, município de Upanema/RN. 2016. 78f. (Doutorado em manejo de solo e água) Programa de Pós Graduação em Extensão Rural, Universidade Federal do Semiárido.

DAHMER, G. W. Diálogo de saberes etnopedológicos multiculturais entre agricultores tradicionais do Vale do Ribeira - Adrianópolis/PR / Gilson Walmor Dahmer. - Curitiba. 2018. 110 p. (Doutorado em Agronomia) - Programa de Pósgraduação em Ciência do Solo. Setor de Ciências Agrárias, Universidade Federal do Paraná. Brasil.

DAWOE, E.K.; QUASHIE-SAM J.; ISAAC, M.E.; OPPONG, S.K. Exploring farmers' local knowledge and perceptions of soil fertility and management in the Ashanti Region of Ghana. Geoderma, v.179, p. 96-103, 2012.

EMBRAPA. Sistema Brasileiro de Classificação de Solos. Brasília; Rio de Janeiro, Embrapa Solos, 2006.

EMBRAPA. Centro Nacional de Pesquisa de Solos. Manual de métodos de análise de solo. Rio de Janeiro, 2011.

ERICKSEN, P.J.; ARDÓN, M. Similarities and differences between farmer and scientist views on soil quality issues in central Honduras. Geoderma, v.111, p. 233248, 2003.

FREIRE, P. Extensão ou comunicação? Rio de Janeiro: Paz e Terra, 1983.

GEILFUS, F. 80 herramientas para el desarrollo participativo: diagnóstico, planificación, monitoreo, evaluación. San José: Instituto Interamericano de Cooperación para la Agricultura, 2002.

GOMES J.C.C. As bases epistemológicas da Agroecologia. In. CAPORAL, F.R.; AZEVEDO, E.O. Princípios e perspectivas da agroecologia. Instituto Federal do Paraná, 2011.

GOMES, J.C.C. Pluralismo metodológico en la producción y circulación del conocimiento agrário: fundamentación epistemológica y aproximación empirica a casos del sur de Brasil.1999.379f. (Doutorado em Agronomia) - Programa de Doctorado en Agroecología, Campesinato e Historia Instituto de Sociología y Estudios Campesinos, Universidade de Córdoba, Espanha.

IBGE, Instituto Brasileiro de Geografia e Estatística. Manual técnico da vegetação brasileira. 2. ed. Rio de Janeiro, 2012. Disponível em: 
https://biblioteca.ibge.gov.br/visualizacao/livros/liv63011.pdf. Acesso em: 30 out. 2019.

IPARDES, INSTITUTO PARANAENSE DE DESENVOLVIMENTO ECONÔMICO E SOCIAL. Cadernos estatísticos dos municípios. Disponível em: www.ipardes.gov.br/MontaCadPdf1.php?Municipio=83350. Acesso em: 25 abr. 2018.

KRASILNIKOV, P.V.; TABOR, J.A. Perspectives on utilitarian ethnopedology. Geoderma, v. 111, p. 19-26, 2003.

LIMA, A.C.R.; HOOGMOED W.B.; BRUSSAARD L.; ANJOS F.S. Farmers' assessment of soil quality in rice production systems. Wageningen Journal of Life Sciences, v.58, n 1-2, p.31-38, 2011.

MAIRURA, F.S.; MUGENDI, D.N.; MWANJE, J.I.; RAMISCH, J. J; MBUGUA, P. K.; CHIANU, J. N. Integrating scientific and farmers evaluation of soil quality indicators in Central Kenya. Geoderma, v. 139, n. 1, p. 134-143, 2007.

MARQUES, R.; MOTTA, A.C.V. Análise química do solo para fins de fertilidade. In: LIMA, M.R. et al. (Org.) Manual de diagnóstico da fertilidade e manejo dos solos agrícolas. 2. Universidade Federal do Paraná, Departamento de Solos e Engenharia Agrícola, 2003.

MORRETES. Decreto $n^{\circ}$ 11/2011, de 12/03/2011. Declara em situação anormal, Caracterizada como estado de calamidade pública a área do município afetada por Enxurradas ou Inundações Bruscas. Disponível em: https://goo.gl/FFAoPM. Acesso em: 11 dez. 2018.

OSUNADE, M.A. Soil Suitability Classification by Small Farmers. The Professional Geographer, v. 40, n. 2, p. 194-201, 1988.

OUDWATER, N.; MARTIN, A. Methods and issues in exploring local knowledge of soils. Geoderma, v.11, p. 387-401, 2003.

PALACIO V.E.A.; ARRIAGA C.M.O. Clasificación campesina de suelos una metodología para para el desarrollo sustentable en el agro. Revista Ideas Ambientales, v. 2, n. 2, p. 199-207, 2005.

PORTELA, J.C.; SILVA, J.F.; DIAS, N.S.; PORTO, V.C.N.; VIANA, I.M. Etnopedologia na classificação de solos em assentamentos rurais no oeste Potiguar. Cadernos de Agroecologia. v. 10, n. 3, p.87, 2015. Disponível em: http://revistas.aba-agroecologia.org.br/index.php/cad/article/view/19038. Acesso em: 31 out. 2018.

PRUDENCIO, K. Metodologia de pesquisa. Curitiba: UFPR, 2011.

QUEIROZ, J.S.; NORTON, B.E. An assessment of an indigenous soil classification used in the caatinga region of Ceará State, Northeast Brazil. Agricultural Systems v. 39, n. 3, p. 289-305, 1992. 
ROZEMBERG, B. O saber local e os dilemas relacionados à validação e aplicabilidade do conhecimento científico em áreas rurais. Cadernos de Saúde Pública, v. 23, n.1. p. 97-105, 2007.

SANTOS, R.D.; LEMOS, R.C.; SANTOS, H.G.; KER, J.C.; ANJOS, L.H.C. Manual de descrição e coleta de solo no campo. Viçosa, Sociedade Brasileira de Ciência do Solo, 2005.

SIDERIUS, W.; BAKKER, H. Toponymy and soil nomenclature in the Netherlands. Geoderma, v. 111, n. 3, p. 521-536, 2003.

SILLITOE, P. Knowing the land: soil and land resource evaluation and indigenous knowledge. Soil Use and Management, v. 14, n. 4, p. 188-193, 1998.

STRACHULSKI, J.; FLORIANI, N. Formação do sistema agrário na região do Paraná tradicional: um estudo de caso da comunidade rural Linha Criciumal em Candido de Abreu. Extensão Rural, Santa Maria, v. 21, n. 3, p. 146-174, 2014. Disponível em: https://periodicos.ufsm.br/extensaorural/article/view/8462/pdf. Acesso em: 31 jul. 2019.

TALAWAR, S.; RHOADES R.E. Scientific and local classification and management of soils. Agriculture and Human Values, v. 15, n. 1, p. 3-14, 1998. 